\title{
Compact and General Strategy for Solving Current and Potential Distribution in Electrochemical Cells Composed of Massive Monopolar and Bipolar Electrodes
}

\author{
A. N. Colli ${ }^{\mathrm{a}, \mathrm{b}, \mathrm{z}}$ and H. H. Girault ${ }^{\mathrm{a}, *}$ \\ ${ }^{a}$ Laboratoire d'Electrochimie Physique et Analytique, École Polytechnique Fédérale de Lausanne, EPFL, \\ Valais Wallis, CH-1951 Sion, Switzerland \\ ${ }^{b}$ Universidad Nacional del Litoral, CONICET, Programa de Electroquímica Aplicada e Ingeniería Electroquímica \\ (PRELINE), Facultad de Ingeniería Química, S3000AOM Santa Fe, Argentina
}

\begin{abstract}
A compact, fast and general algorithm based on Dirichlet boundary conditions for the potential field is derived to enable the calculation of local current distribution, shunt currents and the local potential distribution on massive electrodes in electrochemical cells of any type of geometry in three dimensions, composed of bipolar electrodes at an unknown floating potential and/or terminal monopolar electrodes. The algorithm allows performing the calculation of current-potential distributions and bypass currents for a fixed cell potential (potentiostatic) or a fixed cell current (galvanostatic) enforced to the cell. The proposed approach can be extended to take into account concentration variations of one or several species inside the cell or electrical conductivity variations due to the presence of separators or liquid-gas-solid phases. In order to validate the algorithm, a detailed comparison, between the suggested strategy with experimental results is made in the case of secondary current distribution for $i$ ) a segmented one bipolar electrode $i i$ ) a cell stack composed of 14 bipolar electrodes in the industrial process of alkaline water electrolysis. The proposed tool can help designers to develop more efficient electrochemical reactors by comparing results using different electrode materials, electrolytes and cell designs.

(C) The Author(s) 2017. Published by ECS. This is an open access article distributed under the terms of the Creative Commons Attribution 4.0 License (CC BY, http://creativecommons.org/licenses/by/4.0/), which permits unrestricted reuse of the work in any medium, provided the original work is properly cited. [DOI: 10.1149/2.0471711jes] All rights reserved.

(cc) BY
\end{abstract}

Manuscript submitted April 13, 2017; revised manuscript received June 5, 2017. Published June 22, 2017. This paper is part of the JES Focus Issue on Mathematical Modeling of Electrochemical Systems at Multiple Scales in Honor of John Newman.

Current-potential distributions are among the most significant parameters influencing the operation of monopolar or bipolar electrochemical reactors. ${ }^{1}$ Non-uniform current-potential distribution due to the electrolyte inlet and outlet channels can result in several problems. For example, in electroplating the deposit thickness distribution and morphology are directly linked to the current distribution. ${ }^{2}$ Also, in a case where multiple electrode reactions take place simultaneously, for example during electrodeposition of multiple metals to form alloys, the alloy composition is controlled by the overpotential distribution. Other examples include cases where hydrogen evolution is a parasitic side reaction during metal deposition and undesirable catalyst oxidation during oxygen evolution, where the current efficiency and catalyst corrosion rate again highly affected by the overpotential distribution. Additionally, the power required for operating an electrochemical cell and particularly the ohmic loss are also dependent on the current distribution. Finally, the correct interpretation of experimental data hinges on understanding the range of current densities to which the tested electrode has been subjected.

The current distribution is largely determined by geometric factors such as the shape of the cell, the location of the cathodes relative to the anodes and the placement of bipolar electrodes. ${ }^{3-5}$ Additionally, current distribution will be affected by hydrodynamic conditions, ${ }^{6}$ composition and conductivity of the electrolyte, conductivities of the electrode and catalyst material, electrode kinetics and on the mass transfer rates of reactants and products to and from reaction sites.

Bipolar electrochemical reactors are used in membrane-less cells for chlorate production, ${ }^{7}$ molten salt electrolysis, ${ }^{8}$ wastewater disinfection ${ }^{9}$ and electrocoagulation-electroflotation process ${ }^{10}$ and in electrochemical cells with a membrane for water electrolysis, ${ }^{11}$ redox flow batteries, ${ }^{12}$ and chlor-alkali industry. ${ }^{13}$ Bipolar electrolyzer design is attractive for industrial processes due to the simplified design and construction where no busbars are required inside the stack, and the ability to operate the cell at much higher voltages and much lower currents than in monopolar cells. Although a good design of bipolar

\footnotetext{
*Electrochemical Society Member.
}

${ }^{\mathrm{z}}$ E-mail: ancolli@gmail.com cells results in practically uniform current distribution, it is still important to be able to determine the potential distribution and shunt (bypass, leakage or parasitic) currents in these stacks. Shunt currents may become significant in presence of common conductive electrolyte pathways under electrical potential gradient, leading to corrosion and power loss problems.

Since boundary conditions at the electrode surface of a bipolar electrode cannot be formulated explicitly, the current density on the bipolar electrode must be obtained from calculations. A problem like this is too complex in order to find a mathematically closed-form solution. Apart from the simple geometries and simple kinetic and mass transfer conditions, problems of current distribution can be solved only trough numerical techniques. ${ }^{14}$ Since some decades, numerical simulations have become central to a vast range of scientific areas. As an important tool for predictive process design and for the scale-up of cells and processes (and scale-down of industrial processes for laboratory testing), simulations and modelling can replace a large number of experiments. Additionally, simulations allow sensitivity analysis of different parameters to direct research efforts to obtain most significant improvements.

Theoretical analysis of current-potential distribution in electrochemical reactors has been one of the major subjects in electrochemical engineering. However, most of the reports focusing on modelling current-potential distributions for a stack of bipolar cells use simplified models with electrical analogies. ${ }^{7,15-17}$ Models considering an analogy with heat transfer problems, ${ }^{18,19}$ 2D models with linear kinetics ${ }^{20}$ or even more fundamental models where the potential of bipolar electrodes were enforced ${ }^{21}$ or imposing which area of the bipolar electrodes act as cathode or anode ${ }^{8}$ have also been reported, although some theoretical work has been done considering more complex models, for example to obtain the floating potential in a bipolar nanoparticle film at liquid-liquid interface..$^{22}$

The goal of this paper is to provide a general, compact and fast strategy based on Dirichlet boundary conditions (BC) for the potential field in order to design and/or evaluate electrochemical reactors composed of monopolar or bipolar electrodes, not to discuss the already well-known interpretation of the potential-current distribution in bipolar or monopolar reactors. The developed numerical algorithm 
can predict floating potentials of bipolar electrodes, shunt currents and potential and current distributions in the bulk electrolyte and at the metal-solution interfaces. The proposed tool can help the designer to develop more efficient electrochemical reactors by comparing different situations and can be extended to take into account concentration variations of one or several species.

\section{Theoretical Considerations}

A general electrochemical system composed of electrodes, electrolyte, membranes and insulators is considered. The main hypothesis is that the conductivity of the electrodes is much higher than the conductivity of the electrolyte giving what it is called equipotential metal phases (common metals have a conductivity at least 5 orders of magnitude higher than the most conductive electrolytic solution).

Inside the cell, the current density is directly related to the ionic flux. The flux is described in terms of diffusion of ions across a concentration gradient, migration of charged ions down the electric field and transport of ions due to bulk electrolyte convection. ${ }^{23}$ For simplicity, and without loss of generality, it is assumed that in the interior of an electrolytic cell the electroneutrality is retained, absence of concentration gradients and steady-state conditions. Therefore, Laplace's equation in $3 \mathrm{D}$ reads ${ }^{1,24}$

$$
\nabla \cdot \kappa \nabla \phi_{\mathrm{s}}=0
$$

where $\phi_{\mathrm{s}}$ represents the local electrical potential in the solution phase and $\kappa$ the electrical conductivity that can vary with local coordinates inside the solution phase due to the existence of membranes or different phases.

Equation 1 has to be solved by a proper algorithm. It should be noted that the electrode kinetics, which do not appear explicitly in Equation 1, establish the boundary conditions required for its solution. ${ }^{1}$ Then, the electrode kinetics may influence significantly the current density distribution.

Boundary conditions. - At insulating walls or symmetry axes, the gradient of electrical potential normal to the boundary vanishes due to no flux of species

$$
\left.\frac{d \phi}{d n}\right|_{\mathrm{w}}=0
$$

where $n$ represents the coordinate normal to the boundary in direction of the interior of the electrolyte.

The electrochemical reactions occurring at the electrode interfaces result in a discontinuity in the potential field. There is a relationship, usually non-linear, between the potential drop across the metal-solution interface and the crossing current. Thus, the current distribution at the electrode surfaces is determined by

$$
j_{\mathrm{k}}=\sum j_{\mathrm{k}}^{\mathrm{i}} ; j_{\mathrm{k}}^{\mathrm{i}}=f\left(T, \text { kinetic parameter }^{\mathrm{i}}, \phi_{\mathrm{m}}, \phi_{\mathrm{s}, \mathrm{e}}, E_{0}^{\mathrm{i}}\right)
$$

Now, the flow of current in the solution phase in the vicinity of the electrodes, according to Faraday's law of electrolysis, will be equal to the rate of electrochemical reaction, and the potential drop in the electrolyte is governed by the Ohm's law. In this way, the current density, $j$, at any point of the electrode is determined by the local potential gradient, electrical conductivity and flux of all species, which can usually be expressed by the following equation

$$
j_{\mathrm{Ohm}}=-\left.\kappa \frac{d \phi_{\mathrm{s}}}{d n}\right|_{\mathrm{e}}=j_{\mathrm{k}}
$$

or

$$
j_{\mathrm{Ohm}}-j_{\mathrm{k}}=f\left(\phi_{\mathrm{s}, \mathrm{e}}\right)=0
$$

An iterative Newton-Raphson procedure was employed in order to impose a stable Dirichlet boundary condition for the potential field. The kinetic expressions at electrodes are linearized about a trial solution, then the linearized problem is solved and the resulting solution is used for next iteration. The process is repeated until convergence is reached. In this way, to find the potential profile in the vicinity of the electrodes, the mentioned Newton-Raphson approximation applied to Equation 5 can be expressed as

$$
\phi_{\mathrm{s}, \mathrm{e}}^{\mathrm{r}+1}=\phi_{\mathrm{s}, \mathrm{e}}^{\mathrm{r}}-\frac{\left(j_{\mathrm{Ohm}}-j_{\mathrm{k}}\right)}{\frac{d\left(j_{\mathrm{Ohm}}-j_{\mathrm{k}}\right)}{d \phi_{\mathrm{s}, \mathrm{e}}}} \approx \phi_{\mathrm{s}, \mathrm{e}}^{\mathrm{r}}-\frac{\left(j_{\mathrm{Ohm}}-j_{\mathrm{k}}\right)}{\frac{\kappa}{\Delta n}-\frac{d\left(j_{\mathrm{k}}\right)}{d \phi_{\mathrm{s}, \mathrm{e}}}}
$$

Here, the following additional approximation

$$
\frac{d}{d \phi_{\mathrm{s}, \mathrm{e}}} j_{\mathrm{Ohm}}=-\left.\frac{d}{d \phi_{\mathrm{s}, \mathrm{e}}} \kappa \frac{d \phi_{\mathrm{s}}}{d n}\right|_{\mathrm{e}} \approx-\kappa \frac{d}{d \phi_{\mathrm{s}, \mathrm{e}}}\left(\frac{\left.\phi\right|_{\mathrm{n}+\Delta \mathrm{n}}-\left.\phi\right|_{\mathrm{e}}}{\Delta n}\right)=\frac{\kappa}{\Delta n}
$$

was used since it is assumed that the potential field is a constant for the present problem and it is necessary only to find the potential distribution at the electrode surface.

Bipolar electrodes. - A bipolar electrode inside an electrochemical cell, under an electric field generated by the difference of potential between the terminal anode and terminal cathode, considering equipotential metal phase, has its own constant potential, not known a priory. Some parts of such electrode act as an anode, other parts as a cathode. To calculate this potential, it is considered that both the oxidation and reduction currents on the bipolar electrode surfaces must be equal for the electrode to remain at constant potential. This can be expressed by the integral constraint of the current over the area of the bipolar electrode

$$
\int j d A=f\left(\phi_{\mathrm{m}}^{\text {bip }}\right)=0
$$

Using the definition of Newton-Raphson, for finding the roots of Equation 8, it is

$$
\phi_{\mathrm{m}}^{\mathrm{bip}, \mathrm{r}+1}=\phi_{\mathrm{m}}^{\mathrm{bip}, \mathrm{r}}-\frac{f\left(\phi_{\mathrm{m}}^{\mathrm{bip}, \mathrm{r}}\right)}{f^{\prime}\left(\phi_{\mathrm{m}}^{\mathrm{bip}, \mathrm{r}}\right)}=\phi_{\mathrm{m}}^{\mathrm{bip}, \mathrm{r}}-\frac{\int j d A}{\frac{d}{d \phi_{\mathrm{m}}^{\text {bip, }}} \int j d A}
$$

where

$$
j=j_{\mathrm{k}, \mathrm{a}}+j_{\mathrm{k}, \mathrm{c}}
$$

Potentiostatic control.-Under potentiostatic control, the terminals have a known potential difference. Thus, it is necessary to solve Equation 1 subject to the boundary conditions given by Equation 2 at insulating walls or symmetry planes, Equation 6 in the proximities of the terminal electrodes with known electrode potentials and, also, in the proximities of bipolar electrodes with unknown potential (Equation 9 for each bipolar electrode). The developed algorithm that performs the calculation of the current distribution, when potentiostatic mode applies, is shown in Figure 1.

Galvanostatic control.-When terminal electrodes are current feeders at a fixed known current, the system is in galvanostatic control and the potential difference between the anode floating at an unknown potential and the cathode connected to the ground is obtained by performing an integration similar to Equation 8 over the anode surface

$$
\int j d A=I \Rightarrow \int j d A-I=f\left(U_{\text {cell }}\right)=0
$$

Using Newton-Raphson again to Equation 11, it is

$$
U_{\text {cell }}^{\mathrm{r}+1}=U_{\text {cell }}^{\mathrm{r}}-\frac{f\left(U_{\text {cell }}^{\mathrm{r}}\right)}{f^{\prime}\left(U_{\text {cell }}^{\mathrm{r}}\right)}=U_{\text {cell }}^{\mathrm{r}}-\frac{\int j d A-I}{\frac{d}{d U_{\text {cell }}^{\mathrm{r}}} \int j d A}
$$

It is important to note that when no analytical expression are available for the electrode kinetic, Equations 6, 9 and 12 can still be solved numerically. The developed algorithm that performs the calculation of the current distribution in galvanostatic control is also shown in Figure 1. 


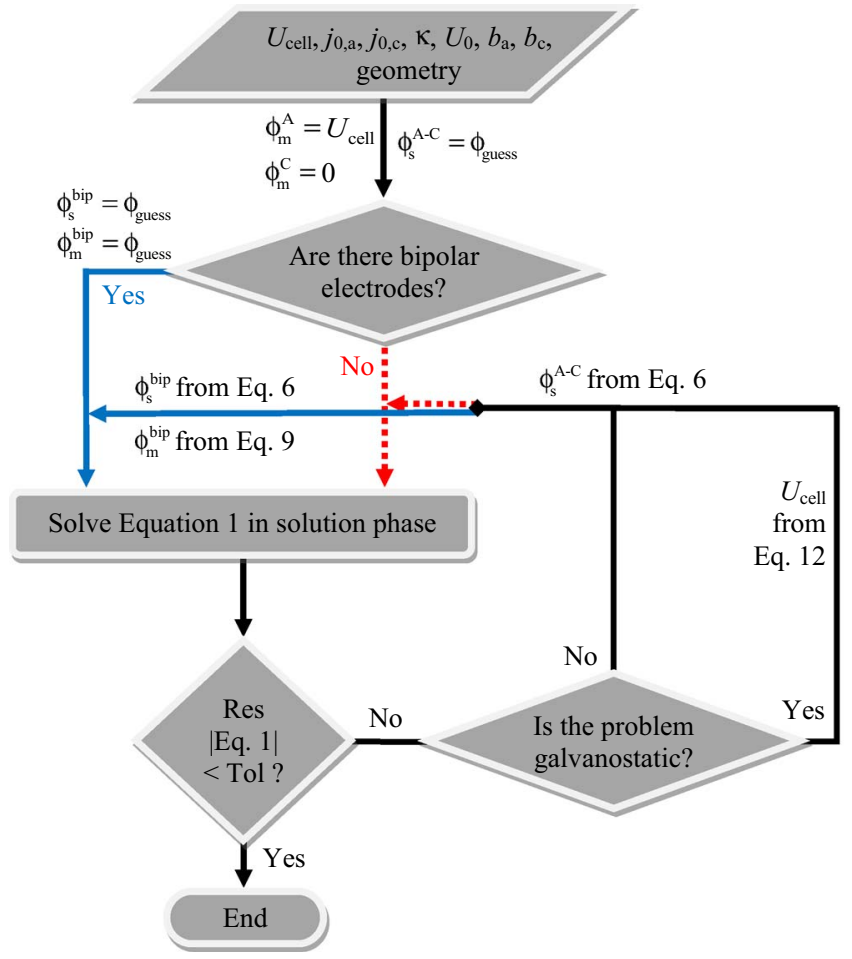

Figure 1. Flow chart for solving the current-potential distribution problem for a monopolar or bipolar electrochemical cell under galvanostatic or potentiostatic operation.

Influence of bubbles on the resistivity.-It is well-known that the presence of bubbles in the electrolyte solution (gas void fraction) and on the electrode surfaces (bubble coverage) cause additional resistances to the ionic transfer and surface electrochemical reactions. These phenomena can be minimized by increasing the working pressure (reducing size of bubbles), fluid flow rate (removing bubbles from electrode surface and in the bulk), use of additives that reduce surface tension or by the use of well-designed cells. ${ }^{25}$ However, this is a key issue that cannot be totally avoided in systems where significant gas evolution takes place, like in water electrolyzers.

Gas void fraction.--In a vertical parallel plate cell, the influence of cell geometry, rate of gas evolution and of superimposed electrolyte flow on the void fraction of gas dispersion has been investigated theoretically and experimentally, arriving to the following relationship ${ }^{26,27}$

$$
\varepsilon=f\left(u_{\mathrm{g}}, u_{1}, u_{0}\right)
$$

Where $u_{\mathrm{l}}$, is the liquid flow velocity, $u_{\mathrm{g}}$ is the volume flow rate per unit cross section of the inter-electrode gap, and $u_{0}$ is the rising velocity of a characteristic single bubble in a stagnant liquid. In a stagnant electrolyte, Equation 13 can be approximated by the following relationship

$$
\varepsilon \approx \frac{\mathrm{R} T I t_{\mathrm{r}}}{\nu_{\mathrm{e}} \mathrm{F} p V_{\text {cell }}}
$$

Equation 14 was derived in a similar way and under the same physical assumptions than Tobias. ${ }^{28}$ Basically, the gas void fraction, $\varepsilon$, is the relationship between the gas volume and the total volume, the former is given by Faraday law and mean residence time of bubbles.

It is also accepted that Bruggeman's equation phenomenologically relates the electrical conductivity with local gas void fraction. ${ }^{26,29}$ This law was experimentally proved in this kind of systems. ${ }^{30}$

$$
\kappa=\kappa_{0}(1-\varepsilon)^{3 / 2}
$$

Bubble coverage.-Bubble coverage needs to be defined to distinguish the active electrode surface area from the geometrical area. ${ }^{31}$
In order to calculate the operational behavior of gas-evolving electrodes, knowledge of the electrode area covered by adhering bubbles is extremely important. The bubble coverage controls the actual current density and thus both the overpotential and the limiting current density. ${ }^{32}$ Bubbles adhering to an electrode insulate a fraction of the surface, making it inactive and increasing the actual local current density on the active part of the electrode.

Although hydrodynamic conditions, current density and to a lesser extent surface roughness and wettability influence bubble coverage, the complexity of these effect cannot be quantitatively described satisfactorily at present. Hence, the following experimentally proven formulation $^{33}$ for vertical electrodes was utilized

$$
\frac{\Theta}{\Theta_{0}}=f\left(\Theta_{0}, \mathrm{Re}\right)
$$

where

$$
\Theta_{0}=0.023(I / A)^{0.3}
$$

here, $I / A$ is the local superficial current density. Equation 17 is a constitutive equation experimentally proved for electro-generated $\mathrm{H}_{2}, \mathrm{O}_{2}$ and $\mathrm{Cl}_{2}$ in stagnant (no forced or significant natural convection) aqueous electrolytes $\left(\mathrm{KOH}, \mathrm{HCl}, \mathrm{H}_{2} \mathrm{SO}_{4}\right)$ at various electrodes materials $\left(\mathrm{Ni}, \mathrm{Pt}, \mathrm{Cu}, \mathrm{C}, \mathrm{Pb}, \mathrm{Hg}\right.$ ) at temperatures between 20 and $30^{\circ} \mathrm{C}^{34}$ Thus, the superficial current density must be distinguished from the actual current density, $j$, by

$$
j=\frac{I / A}{1-\Theta}
$$

Furthermore, gas bubbles adhering to the electrode surface affect the local solution conductivity. ${ }^{35}$ Finally, the gas fraction of the two-phase flow distribution inside the cell can also been predicted by solving, for a given geometry and with any temperature and solution composition, the transport equations for both the gaseous and liquid phases. ${ }^{36}$

\section{Results and Discussion}

Specific boundary conditions for water electrolysis.-For the present simulations and further comparison with experimental results, only an irreversible gas evolution reaction in each position at the electrode was considered. In this case, the anodic and cathodic reactions can be expressed simply as

$$
\begin{gathered}
j_{\mathrm{k}, \mathrm{a}}=j_{0, \mathrm{a}} \exp \left(\frac{\eta_{\mathrm{a}}}{b_{\mathrm{a}}}\right) \\
j_{\mathrm{k}, \mathrm{c}}=-j_{0, \mathrm{c}} \exp \left(\frac{-\eta_{\mathrm{c}}}{b_{\mathrm{c}}}\right)
\end{gathered}
$$

where

$$
\eta_{\mathrm{i}}=\phi_{\mathrm{m}}-\phi_{\mathrm{s}, \mathrm{i}}-E_{0, \mathrm{i}}
$$

being $\eta$ the overpotential, $\phi$ the potential in the metal $(\mathrm{m})$ and solution (s) phase adjacent to the electrode surface, respectively, and $E_{0}$ the equilibrium potential for a reaction $i$ (anodic or cathodic).

Additionally, the metal phase was considered as an equipotential ideal conductor, so the applied potential of cell is given by

$$
\phi_{\mathrm{m}}^{\mathrm{A}}-\phi_{\mathrm{m}}^{\mathrm{C}}=U_{\text {cell }}
$$

Taking into account Equations 18, 19, 20 and 22, and grounding the terminal cathode (i.e. $\phi_{\mathrm{m}}^{\mathrm{C}}=0$ ), and selecting the potential scale so that equilibrium potential of the cathode measured is $E_{0, \mathrm{c}}=0$, the nominal current density of the cell can be expressed as

$$
\begin{gathered}
I / A=\left(1-\Theta_{\mathrm{a}}\right) j_{0, \mathrm{a}} \exp \left(\frac{U_{\text {cell }}-\phi_{\mathrm{s}}^{\mathrm{A}}-U_{0}}{b_{\mathrm{a}}}\right) \\
I / A=-\left(1-\Theta_{\mathrm{c}}\right) j_{0, \mathrm{c}} \exp \left(\frac{\phi_{\mathrm{s}}^{\mathrm{C}}}{b_{\mathrm{c}}}\right)
\end{gathered}
$$


Now equation 9 can be written as

$$
\phi_{\mathrm{m}}^{\mathrm{bip}, \mathrm{r}+1}=\phi_{\mathrm{m}}^{\mathrm{bip}, \mathrm{r}}-\frac{\int\left[\left(1-\Theta_{\mathrm{a}}\right) j_{0, \mathrm{a}} \exp \left(\frac{\phi_{\mathrm{m}}^{\mathrm{bip}, \mathrm{r}}-\phi_{\mathrm{s}, \mathrm{a}}-U_{0}}{b_{\mathrm{a}}}\right)-\left(1-\Theta_{\mathrm{c}}\right) j_{0, \mathrm{c}} \exp \left(-\frac{\phi_{\mathrm{m}}^{\mathrm{bip}, \mathrm{r}}-\phi_{\mathrm{s}, \mathrm{c}}}{b_{\mathrm{c}}}\right)\right] d A}{\int\left[\frac{\left(1-\Theta_{\mathrm{a}}\right) j_{0, \mathrm{a}}}{b_{\mathrm{a}}} \exp \left(\frac{\phi_{\mathrm{m}}^{\mathrm{bip}, \mathrm{r}}-\phi_{\mathrm{s}, \mathrm{a}}-U_{0}}{b_{\mathrm{a}}}\right)+\frac{\left(1-\Theta_{\mathrm{c}}\right) j_{0, \mathrm{c}}}{b_{\mathrm{c}}} \exp \left(-\frac{\phi_{\mathrm{m}}^{\mathrm{bip}, \mathrm{r}}-\phi_{\mathrm{s}, \mathrm{c}}}{b_{\mathrm{c}}}\right)\right] d A}
$$

For galvanostatic operation, at the terminal anode, Equation 12 reads

$$
U_{\text {cell }}^{\mathrm{r}+1}=U_{\text {cell }}^{\mathrm{r}}-\frac{\int\left(1-\Theta_{\mathrm{a}}\right) j_{0, \mathrm{a}} \exp \left(\frac{U_{\text {cell }}^{\mathrm{r}}-\phi_{\mathrm{s}}^{\mathrm{A}}-U_{0}}{b_{\mathrm{a}}}\right) d A-I}{\int \frac{\left(1-\Theta_{\mathrm{a}}\right) j_{0, \mathrm{a}}}{b_{\mathrm{a}}} \exp \left(\frac{U_{\text {cell }}^{\mathrm{r}}-\phi_{\mathrm{s}}^{\mathrm{A}}-U_{0}}{b_{\mathrm{a}}}\right) d A}
$$

where $\Theta$ is given by Equation 17. The proposed algorithm showed in Figure 1, considering Equations 23-26 was implemented successfully using the finite volume method. ${ }^{37,38}$ OpenFOAM free, an open source CFD software, was used to calculate the potential field by solving Equation 1, according to laplacianFoam routine with standard setting for fvSchemes, with variable conductivity $\left(\kappa_{0}\right.$ in the electrolyte and $\kappa$ in the interelectrode gap) in steady state. The absolute tolerance for calculating the potential field was $1 \times 10^{-7}$, and the relative tolerance for each iteration was set to 0.5 . The computational region was divided into a structured uniform mesh of 50000 and 150000 cells in $x-y$ directions for the case $i$ ) and $i$ ), respectively.

Kinetic behavior (simple reaction ${ }^{1}$ ).-As a consequence of the great uncertainty about kinetic parameters reported in literature: i) much of the kinetics are studied at different temperatures, ii) no $I R$ or activity coefficient corrections are usually done, and iii) most of kinetics found in literature were performed at low current densities, ${ }^{39}$ polarization curves from a Nickel disk electrode of $3 \mathrm{~mm}$ diameter (Nickel 99.78\% from ADVENT Research Materials) were performed, as shown in Figure 2, by working at different currents densities. The electrode was polished with sandpaper (\#300 - \#1500) without significant differences in the obtained results for the different roughness, and

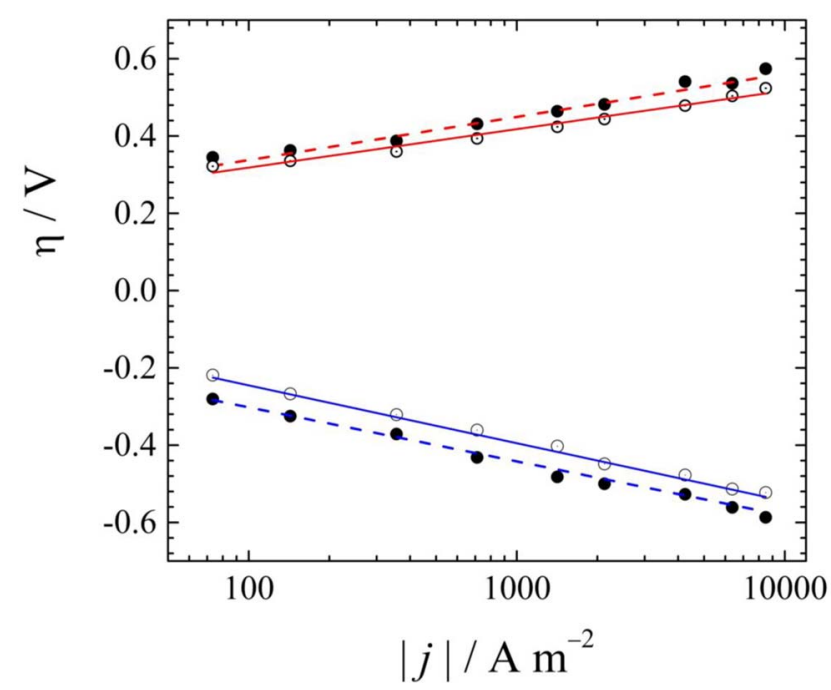

Figure 2. $I R$ corrected polarization curves in $6 \mathrm{M} \mathrm{KOH}$ at 30 and $50^{\circ} \mathrm{C}$. Oxygen (positive overpotential) and hydrogen (negative overpotential) evolution using a $3 \mathrm{~mm} \mathrm{Ni}$ disk. Each experimental point represents a steady-state potential for a given current density. Temperature: $(\odot) 30^{\circ} \mathrm{C}\left(R_{\mathrm{S}}=3.2 \Omega\right),(\bullet)$ $50^{\circ} \mathrm{C}\left(R_{\mathrm{S}}=2.4 \Omega\right)$. Lines: Tafel fitting of experimental measurements (Shown in Tables I and III). a Platinum electrode was used as counter-electrode. All experiments were performed both at $30^{\circ} \mathrm{C}$ and $50^{\circ} \mathrm{C}$ in $6 \mathrm{M} \mathrm{KOH}$.

One of the problems observed with $\mathrm{Ni}$-based materials for water electrolysis is the loss of activity as indicated by the time variation of the cathode and anode potentials. ${ }^{40}$ Thus, instead of making a classical quasi steady-state linear sweep voltammetry, the working electrode potential against $\mathrm{Ag} / \mathrm{AgCl}$ ( $3 \mathrm{M} \mathrm{KCl}$ in a double-junction reference to avoid contamination of the solution by chloride ions) for a given current until steady-state was reached under $\mathrm{N}_{2}$ bubbling and vigorous stirring in order to avoid bubble coverage and to ensure that the reaction rate was not limited by the mass transfer (agitation was increased until no change in potential was found). The same step was repeated for all the currents. At these high currents, there is a significant ohmic drop between the working Ni electrode and the reference electrode inserted into a Luggin capillary. The ohmic resistance was measured for each experiment by impedance spectroscopy, and $I R$ correction employed to eliminate this effect. Finally, the equilibrium potentials in the given conditions were calculated by using the activity coefficients given by Kusik and Meissner ${ }^{41}$ to calculate the overpotential, experimental data were fitted by Tafel equation in semi-logarithmic coordinates, and the fitting parameters are reported in Tables I and III. It is important to point out that the present results are in agreement with those presented also by others. ${ }^{42,43}$

Validation.-For the present numerical modelling, some simplifying assumptions were necessary. In order to validate the algorithm/ strategy that we have developed, comparisons with experimental results are required.

Validation with experimental results from Henquin and Bisang ${ }^{21,44}$.- The proposed model was validated with the experimental results obtained with two undivided reactors electrically connected in series, resulting in a two-cell stack with one bipolar electrode. Usually, this type of cell has symmetrical inlet and outlet manifolds, and thus only one half of the stack was considered. Two different concentrations of $\mathrm{NaOH}(1 \mathrm{M}$ and $3 \mathrm{M}$ ) and three cell currents (1, 3 and 5 A) were used, and hydrogen and oxygen evolution were the cathodic and anodic reaction in the stack, respectively. The experimental current distribution was determined by the segmented electrode method. The electrodes at each reactor were composed of 15 nickel segments $\left(0.05 \mathrm{~m}\right.$ long $(W)$ and $6.1 \times 10^{-3} \mathrm{~m}$ wide ( $y$-direction $\left.)\right)$ insulated from each other by an epoxy resin. The length of one reactor was $0.1 \mathrm{~m}$ $(L / 2, y$-direction). The inter-electrode gap was $0.02 \mathrm{~m}(h)$. Calibrated resistors $(0.02 \Omega)$ were inserted between each segment and the current

Table I. Physicochemical properties and kinetic parameters used in modelling for case $i$ ).

\begin{tabular}{ccc} 
Property & Value & Measured/Calculated \\
\hline$\rho_{0}[\mathrm{NaOH}]=1 \mathrm{M}(\Omega \mathrm{m})$ & $5.59 \times 10^{-2}$ & Experimentally $^{21}$ \\
$\rho_{0}[\mathrm{NaOH}]=3 \mathrm{M}(\Omega \mathrm{m})$ & $2.94 \times 10^{-2}$ & Experimentally $^{21}$ \\
$U_{0}(\mathrm{~V})$ & 1.23 & Theoretically $^{21}$ \\
$b_{\mathrm{a}}(\mathrm{V})$ & $4.85 \times 10^{-2}$ & Experimentally \\
$j_{0, \mathrm{a}}\left(\mathrm{A} \mathrm{m}^{-2}\right)$ & $9.38 \times 10^{-2}$ & Experimentally \\
$b_{\mathrm{c}}(\mathrm{V})$ & $6.08 \times 10^{-2}$ & Experimentally \\
$j_{0, \mathrm{c}}\left(\mathrm{A} \mathrm{m}^{-2}\right)$ & $6.95 \times 10^{-1}$ & Experimentally \\
$p(\mathrm{~Pa})$ & 61800 & Experimentally \\
$t_{\mathrm{r}}(\mathrm{s})$ & 3.75 & Experimentally \\
$\varepsilon \times 10^{2}(1,3,5 \mathrm{~A})$ & $1.4,4,6.6$ & Equation 14 \\
$\kappa / \kappa_{0}(1,3,5 \mathrm{~A})$ & $0.98,0.94,0.90$ & Equation 15
\end{tabular}


feeder. The current distribution at each electrode was determined by measuring the ohmic drop over each resistor.

Although, the gas void fraction varies with the length of vertical electrodes, ${ }^{27,28,30,45}$ current distribution in the direction of the electrode width $(W)$ is neglected due to the electrodes were segmented in horizontal direction $(y)$ in order to obtain the current distribution as a consequence of the existence of a manifold. Thus, in the present validation an average value of the gas void fraction in each segment was considered. Figure 3 shows a simplified scheme of the cell where $x$ and $y$ are the cartesian coordinates (see Figure 2 of Ref. 21 for more details). Table I summarizes the physicochemical properties and kinetic parameters used in the modelling. Figure 4 shows current distributions at the terminal and at the bipolar electrodes for different solution resistivity at $I=1 \mathrm{~A}$. As expected, it can be seen that the current distribution is less uniform, from the experimental and theoretical point of view, when the conductivity is higher. Moreover, it can be seen that the proposed model predicts quite well experimental results. Complementary information is given in Table II with regards to cell voltage and leakage current which is defined as ${ }^{21}$

$$
I^{*}=I^{\mathrm{A}-\mathrm{C}}-\frac{1}{N} \sum_{\mathrm{j}=1}^{N} I_{\mathrm{j}}^{\mathrm{bip}}
$$

showing absolute percentage errors of less than $7 \%$ between simulated and experimental results. Lastly, comparison of the theoretical results obtained by Henquín and Bisang, ${ }^{21,44}$ are also showed in Figure 4 and Table II. Better predictive capabilities can be attributed to the influence of the gas phase included in the present model.

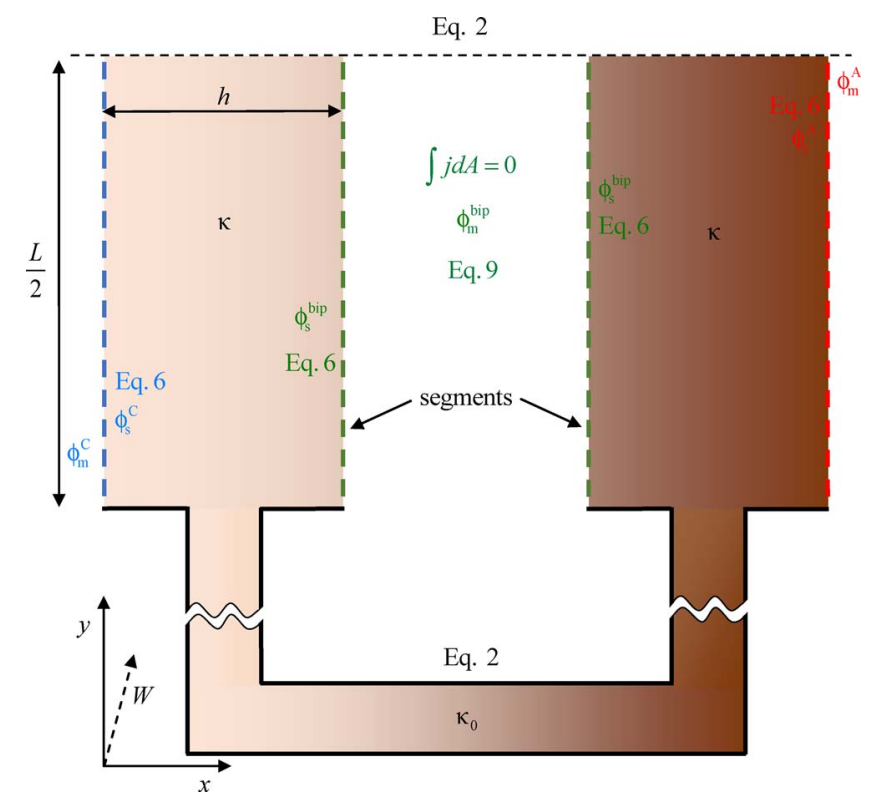

Figure 3. Simplified scheme of the bipolar electrochemical cell used in case $i$ ). Boundary conditions and segmented electrodes are shown in different colors. The force of gravity is acting in direction perpendicular to the $x$ - $y$ plane. Symmetry axis is shown as a dashed line. See Figure 2 of Ref. 21 for more details
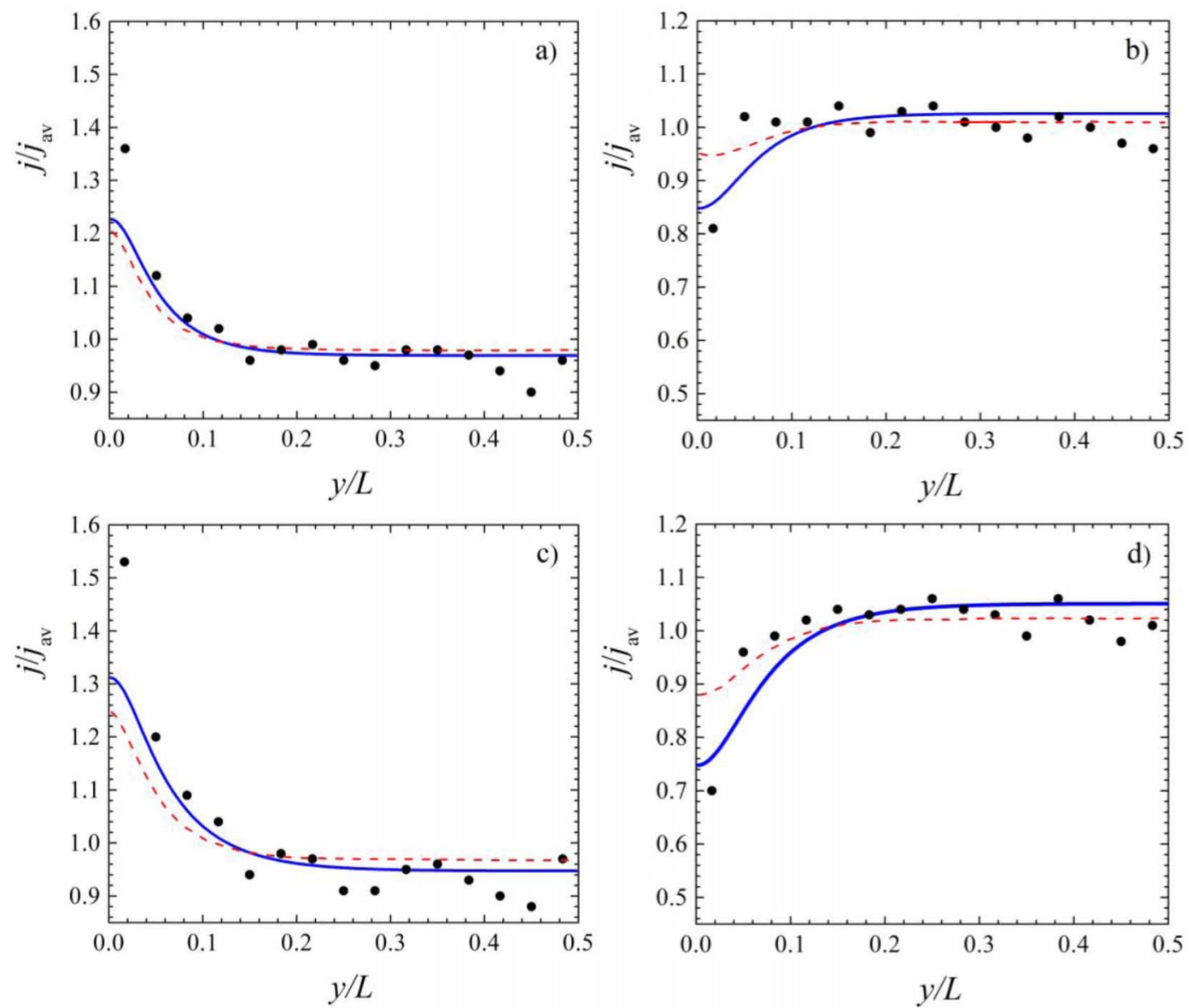

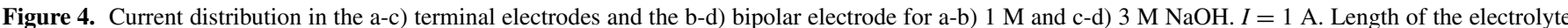

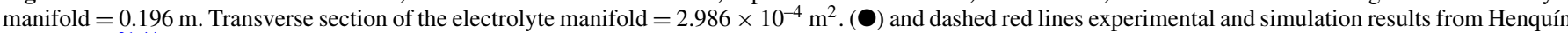
and Bisang, ${ }^{21,44}$ respectively. Full blue lines: simulation results. 
Table II. Comparison between experimental data and simulations results for case $i$ ).

\begin{tabular}{cccccc}
{$[\mathrm{NaOH}]$} & $I(\mathrm{~A})$ & & Experimental & Theoretical $^{* *}$ & $\begin{array}{c}\text { Difference } \\
(|\%|)^{* * *}\end{array}$ \\
\hline \multirow{2}{*}{$1 \mathrm{M}$} & 1 & $U_{\text {cell }}(\mathrm{V})$ & 4.71 & 4.62 & $\mathbf{2 . 0}(\mathbf{5 . 1})$ \\
& & $I^{*}(\mathrm{~mA})$ & 50.0 & 52.7 & $\mathbf{5 . 4}(\mathbf{3 6 . 2})$ \\
& 3 & $U_{\text {cell }}(\mathrm{V})$ & 6.60 & 6.41 & $\mathbf{3 . 0}(\mathbf{0 . 9})$ \\
& & $I^{*}(\mathrm{~mA})$ & 62.2 & 66.4 & $\mathbf{6 . 7}(\mathbf{1 2 . 6})$ \\
& 5 & $U_{\text {cell }}(\mathrm{V})$ & 8.17 & 8.06 & $\mathbf{1 . 3}(\mathbf{1 . 3})$ \\
$3 \mathrm{M}$ & & $I^{*}(\mathrm{~mA})$ & 81.4 & 83.4 & $\mathbf{2 . 5}(\mathbf{7 . 2})$ \\
& 1 & $U_{\text {cell }}(\mathrm{V})$ & 4.26 & 4.23 & $\mathbf{0 . 7}(\mathbf{7 . 7})$ \\
& & $I^{*}(\mathrm{~mA})$ & 94.8 & 91.5 & $\mathbf{3 . 4}(\mathbf{4 5 . 2})$ \\
& 3 & $U_{\text {cell }}(\mathrm{V})$ & 5.30 & 5.24 & $\mathbf{1 . 2 ( 5 . 1 )}$ \\
& & $I^{*}(\mathrm{~mA})$ & 116.4 & 111.6 & $\mathbf{4 . 1}(\mathbf{3 4 . 6})$ \\
& 5 & $U_{\text {cell }}(\mathrm{V})$ & 6.10 & 6.10 & $\mathbf{0 . 0}(\mathbf{5 . 9})$ \\
& & $I^{*}(\mathrm{~mA})$ & 141.3 & 134.0 & $\mathbf{5 . 1}(\mathbf{3 0 . 4})$
\end{tabular}

**There was added an extra voltage due to the experimental resistances used to measure current distribution.

***Values between brackets correspond to the differences obtained by Henquín and Bisang. ${ }^{21}$

The potential-current distributions have been well discussed in the original paper from Henquín and Bisang, ${ }^{21}$ so this discussion is not repeated here. However, the originality is more on the complexity and generality of the problem. The present strategy to solve this problem is very general. In fact, the same algorithm can solve the secondary current distribution in monopolar or bipolar reactors with unknown electrodes potential under galvanostatic or potentiostatic modes. The same problem was solved also in Ref. 21, with even more simplified assumptions (fixed bipolar potential for the bipolar electrode and imposing which area of the electrode acts as anode or cathode) under galvanostatic conditions without influence of a gas phase. In this case, three loops were required for solving a simplified version of the problem, while our method is able to solve it in one loop. This highlights that we are presenting an original and quite general strategy to model current and potential distribution for cell stack based on Newton-Raphson equations.

Validation with experimental results from Comninellis et al. ${ }^{46}$.Finally, the model proposed in this paper was validated with experimental results from Comninellis et al. ${ }^{46}$ for hydrogen and oxygen evolution from alkaline water electrolysis under flow conditions. Figure 5 shows a half-cell composed of 14 bipolar nickel electrodes and two current feeders of the same dimensions, $0.396 \mathrm{~m} \times 0.017 \mathrm{~m} \times$ $0.002 \mathrm{~m}(L \times W \times \delta)$ used in the experiments (see Figure 1 of Ref. 46 for more details). The electrodes were separated from each other by insulating spacers at a fixed distance of $0.0033 \mathrm{~m}(h)$. The electrolyte was pumped through the electrode stack with an average velocity of $0.5 \mathrm{~m} \cdot \mathrm{s}^{-1}$, and its temperature was kept constant at $50^{\circ} \mathrm{C}$ using a thermostat. The minimum simulated stack potential in this work was $30 \mathrm{~V}$ in order to ensure that all bipolar cells were active. $\Theta \approx 0$ was assumed due to the high flow rate, ${ }^{33}$ and Equations $23-26$ were used in conjunction with information given in Table III to perform the simulations showed in Figures 5 to 8. Figure 5 shows the computed potential field for $U_{\text {cell }}=60 \mathrm{~V}$, showing how a non-proper design of the cell can lead to a non-uniform potential distribution, mainly near the edges of terminal electrodes. Figure 6 presents the effect of KOH concentration on the theoretical and experimental current-potential curves obtained with the bipolar reactor of 15 cells. The proposed model agrees with experimental results except at regions of low current density where the electrical field inside the reactor cannot polarize all the electrodes.

Comninellis et al. ${ }^{46}$ measured the flow rate of evolved gas from water electrolysis using a bubble flowmeter and calculated the shunt currents from the difference of the measured and the theoretical gas flow rate, supposing no shunt currents. The theoretical and experimental shunt currents are shown in Figure 7 for two different $\mathrm{KOH}$

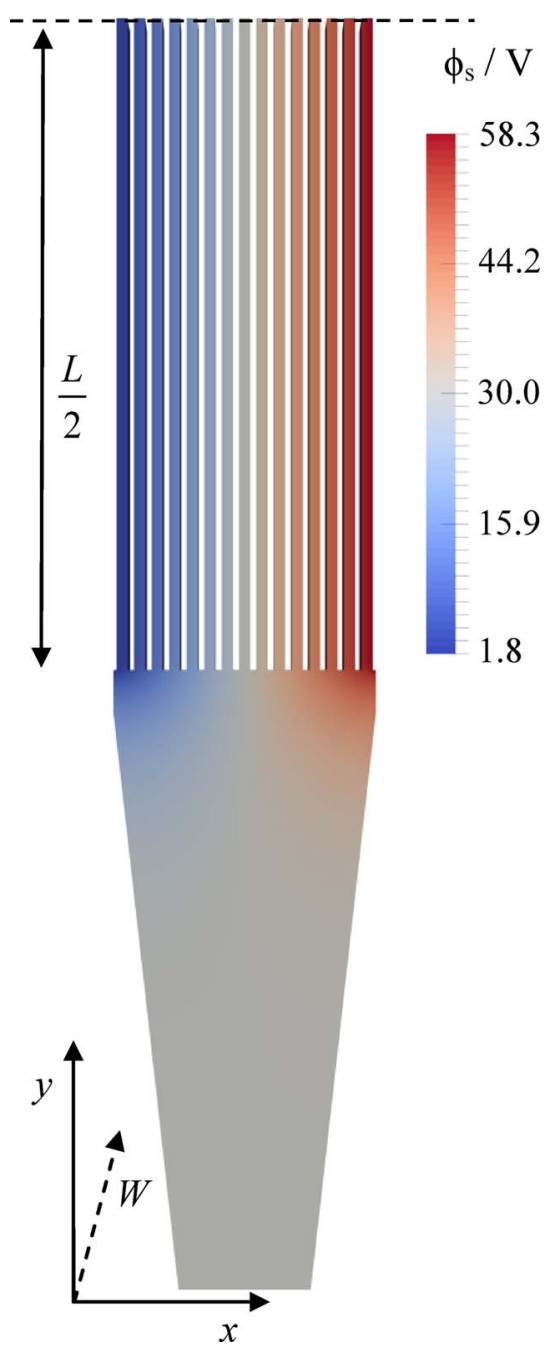

Figure 5. Potential distribution in half of the reactor used by Comninellis et al. ${ }^{46} U_{\text {cell }}=60$ V. $I=41.84$ A. $[\mathrm{KOH}]=0.325 \mathrm{M} . T=50^{\circ} \mathrm{C}$. Symmetry axis is shown as a dashed line. See Figure 1 of Ref. 46 for more details.

concentrations. To quantify the effects of shunt currents on the efficiency of the cell, the current efficiency of the cell stack $(C E)$ is defined as ${ }^{8}$

$$
C E=\frac{I^{\mathrm{A}-\mathrm{C}}+\sum_{\mathrm{j}=1}^{N} I_{\mathrm{j}}^{\mathrm{bip}}}{(N+1) I^{\mathrm{A}-\mathrm{C}}}
$$

Table III. Physicochemical properties and kinetic parameters used in modelling for case $i$ ).

\begin{tabular}{ccc} 
Property & Value & Measured/Calculated \\
\hline$\kappa_{0}[\mathrm{KOH}]=0.325 \mathrm{M}\left(\mathrm{S} \mathrm{m}^{-1}\right)$ & 10.13 & Theoretically $^{47}$ \\
$\kappa_{0}[\mathrm{KOH}]=0.5 \mathrm{M}\left(\mathrm{S} \mathrm{m}^{-1}\right)$ & 15.32 & Theoretically $^{47}$ \\
$U_{0}(\mathrm{~V})$ & 1.205 & Theoretically $^{41}$ \\
$b_{\mathrm{a}}(\mathrm{V})$ & $4.32 \times 10^{-2}$ & Experimentally $^{-2}$ \\
$j_{0, \mathrm{a}}\left(\mathrm{A} \mathrm{m} \mathrm{m}^{-2}\right)$ & $6.3 \times 10^{-2}$ & Experimentally $^{-2}$ \\
$b_{\mathrm{c}}(\mathrm{V})$ & $6.35 \times 10^{-2}$ & Experimentally $^{-2}$ \\
$j_{0, \mathrm{c}}\left(\mathrm{A} \mathrm{m}^{-2}\right)$ & $2.16 \times 10^{1}$ & Experimentally \\
$u_{\mathrm{l}}\left(\mathrm{m} \mathrm{s}^{-1}\right)$ & 0.5 & Experimentally \\
$\varepsilon$ & $0-0.141$ & Equation $13^{26}$ \\
$\kappa / \kappa_{0}$ & $1-0.796$ & Equation 15
\end{tabular}




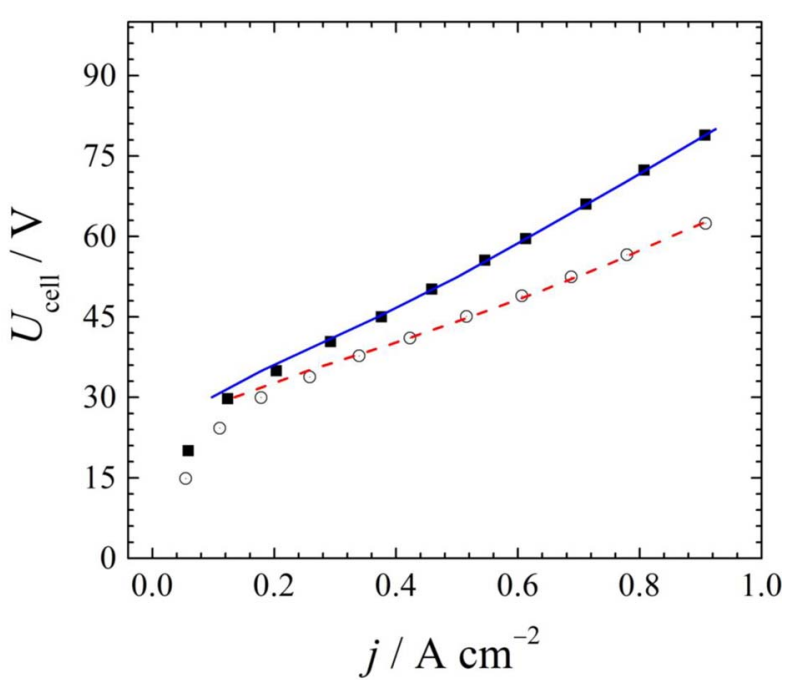

Figure 6. Potential-current curves for a bipolar stack with 15 cells obtained at different $\mathrm{KOH}$ concentrations. $(\square) 0.325 \mathrm{M}$ and $(\odot) 0.5 \mathrm{M}, T=50^{\circ} \mathrm{C}$. Full blue and dashed red lines: simulation results.

Thus, the inset in Figure 7 displays $C E$ as a function of current density, showing that $C E$ improves when $j$, and therefore $U_{\text {cell }}$, increases. This can be explained by the fact that an increasing electric field inside the cell favors polarization of the bipolar electrodes. In other words, the polarization resistance decreases with current.

Figures 6 and 7 show that with information of kinetic data, geometry of cell and conductivity of solution, it is possible to reproduce with high precision the $U_{\text {cell }}$ vs. $j$ behavior and the shunt current of such a complex system, when $\eta$ vs. $\ln j$ behavior is linear. However, this requirement for the linearity is not a serious limitation at least for water electrolysis, as commercial systems operate at high current densities. The proposed model can accurately predict the secondary current distribution at each electrode, bypass current and floating potentials of each bipolar electrode. That information is useful in order to optimize a given system.

Finally, the advantage of the proposed strategy lies in having even much more information than what the experiments show. As for ex-

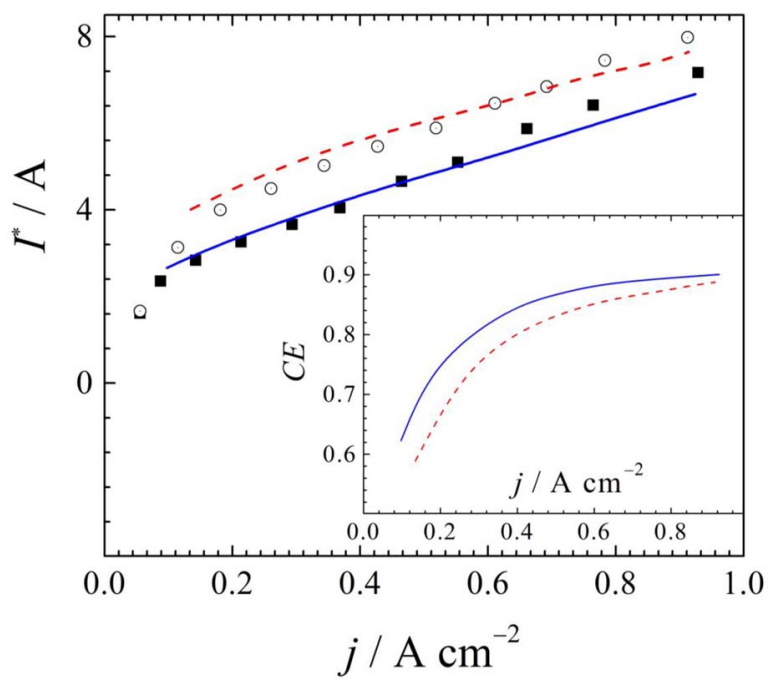

Figure 7. Bypass current as a function of current density. Experimental result from Comninellis et al. ${ }^{46}[\mathrm{KOH}]=(\boldsymbol{\square}) 0.325 \mathrm{M}$ and $(\odot) 0.5 \mathrm{M}, T=50^{\circ} \mathrm{C}$. Full blue and dashed red lines: simulation results. Inset: Simulation results of current efficiency of the bipolar stack as a function of the current density. Full blue line: $[\mathrm{KOH}]=0.325 \mathrm{M}$, dashed red line: $[\mathrm{KOH}]=0.5 \mathrm{M}$.

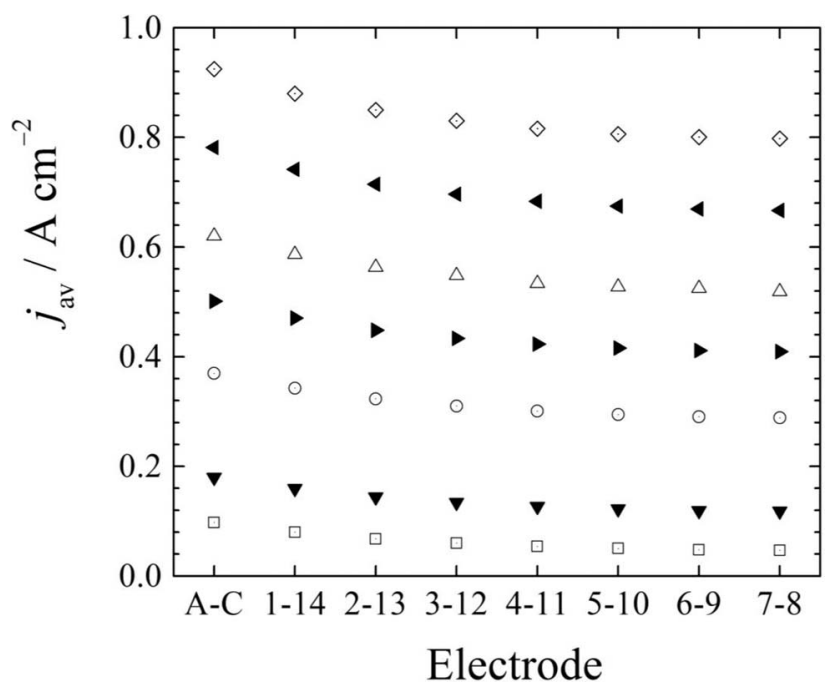

Figure 8. Dependence of the average current density for the $j^{\text {th }}$ bipolar electrode in the cell stack (for simplicity, results of half of the cell stack is shown). $[\mathrm{KOH}]=0.325 \mathrm{M} . T=50^{\circ} \mathrm{C}$. From top to bottom: $U_{\text {cell }}=80,70,60,52.5$, 45,35 and $30 \mathrm{~V}$.

ample, current distribution along each electrode, identify which part act as anode or cathode or the average values of current densities for each bipolar electrode that are shown in Figure 8. Although symmetry with respect to the central electrodes does not exist (due to the different polarization curves used for the cathodic and anodic processes), small differences were found between $j_{\mathrm{av}, \mathrm{j}}$ and $j_{\mathrm{av}, \mathrm{N}+1-\mathrm{j}}$.

\section{Conclusions}

An easy to understand, fast, compact and general strategy was developed, by imposing Dirichlet boundary conditions for the potential field, in order to obtain current density distribution, shunt currents and potential of electrodes in cells composed of bipolar and/or terminal monopolar electrodes, both as galvanostatic or potentiostatic operation.

The proposed algorithm, considering secondary current distribution with influence of bubble coverage and/or change of effective resistivity due to bubbles, was validated by comparing experimental data of $i$ ) a segmented two undivided reactors electrically connected in series, which constitutes a bipolar electrochemical stack with one bipolar electrode ${ }^{21}$ and $i$ i) an electrolyzer stack composed of 14 bipolar nickel electrodes and two current feeders of the same dimensions, ${ }^{46}$ giving in both cases a close agreement between experimental and predictive results.

The present method can be adapted, also, to more general problems taking into account concentration or conductivity variations, by solving the relevant mass transfer-gas phase equations and the potential field with Dirichlet boundary conditions, simultaneously. It is applicable not only to conventional electrochemical cell with massive electrodes but also to more complicated systems such as corrosion cells in which the anodic and cathodic areas are not separated. Finally, the proposed tool can help the designer in scale-up situations or to develop more efficient electrochemical reactors by comparing results using different electrode materials, electrolytes and cell designs.

\section{Acknowledgments}

This work was supported by Commission for Technology and Innovation (CTI) and EXEN Sàrl of Switzerland (project number17748.1 PFEN-IW) and the Agencia Nacional de Promoción Científica y Tecnológica (ANPCyT), Consejo Nacional de Investigaciones Científicas y Técnicas (CONICET) and Universidad Nacional del Litoral (UNL) 
of Argentina. The authors thank Dr. Pekka Peljo, Dr. Alberto Battistel and Dr. Heron Vrubel for helpful discussions.

\section{List of Symbols}

A electrode surface area, $\mathrm{m}^{2}$

$b \quad$ Tafel slope, $\mathrm{V}$

$C E \quad$ current efficiency of the bipolar stack given by Eq. 28

$E_{0} \quad$ equilibrium potential, $\mathrm{V}$

F $\quad$ Faraday constant $=96485, \mathrm{C} / \mathrm{mol}$

$f$ function

$h \quad$ interelectrode gap, $\mathrm{m}$

I current, A

shunt, leakage or bypass current given by Eq. 27, A

current density, $\mathrm{A} / \mathrm{m}^{2}$

exchange current density, $\mathrm{A} / \mathrm{m}^{2}$

electrode length, $\mathrm{m}$

number of bipolar electrodes

coordinate normal to surface, $\mathrm{m}$

partial pressure of the gas liberated at electrodes, $\mathrm{Pa}$

universal gas constant $=8.314, \mathrm{~m}^{3} \mathrm{~Pa} /(\mathrm{K} \mathrm{mol})$

solution resistance, $\Omega$

Reynolds number

residual

temperature, ${ }^{\circ} \mathrm{C}$ or $\mathrm{K}$

tolerance

mean residence time of bubbles, $\mathrm{s}$

fluid (gas or liquid) velocity, $\mathrm{m} / \mathrm{s}$

cell potential, $\mathrm{V}$

equilibrium potential of the anodic reaction considering

$E_{0, \mathrm{c}}=0, \mathrm{~V}$

cell volume, $\mathrm{m}^{3}$

electrode width, $m$

axial coordinate, $\mathrm{m}$

axial coordinate, $\mathrm{m}$

\section{Greek}

anodic

average

cathodic

electrode

gas phase

initial guess

anodic or cathodic

$j^{\text {th }}$ bipolar electrode

given by kinetic expression

liquid phase

metal phase

number of bipolar electrodes

given by Ohm law solution phase

wall

gas-free electrolytic solution

\section{Superscripts}

$\begin{array}{ll}\text { A } & \text { terminal anode } \\ \text { bip } & \text { bipolar electrode } \\ \mathrm{C} & \text { terminal cathode } \\ \mathrm{i} & i^{\text {th }} \text { reaction }(\mathrm{i}=\text { anodic or cathodic }) \\ \mathrm{r} & \text { iteration number } \\ , & \text { derivative }\end{array}$

\section{References}

1. J. Newman and K. E. Thomas-Alyea, Electrochemical Systems, 3rd edition, WileyInterscience, New Jersey, (2004).

2. R. C. Alkire, J. Chem. Educ., 60, 274 (1983)

3. A. N. Colli and J. M. Bisang, J. Electrochem. Soc., 164, E42 (2017).

4. A. N. Colli and J. M. Bisang, Electrochim. Acta, 137, 758 (2014).

5. A. N. Colli and J. M. Bisang, Electrochim. Acta, 113, 575 (2013).

6. A. N. Colli and J. M. Bisang, J. Electrochem. Soc., 160, E5 (2013).

7. I. Rousar, J. Electrochem. Soc., 116, 676 (1969).

8. I. Rousar and J. Thonstad, J. Appl. Electrochem., 24, 1124 (1994).

9. E. R. Henquín, A. N. Colli, M. E. H. Bergmann, and J. M. Bisang, Chemical Engineering and Processing: Process Intensification, 65, 45 (2013).

10. J. Ge, J. Qu, P. Lei, and H. Liu, Sep. Purif. Technol., 36, 33 (2004).

11. N. Guillet and P. Millet, in Hydrogen Production: by Electrolysis, p. 117, Wiley-VCH Verlag GmbH \& Co. KGaA (2015).

12. A. N. Colli, P. Peljo, and H. H. Girault, Chem. Commun., 52, 14039 (2016).

13. D. Pletcher and F. C. Walsh, Industrial Electrochemistry, Chapman and Hall, London, (1993).

14. G. A. Prentice and C. W. Tobias, AlChE J., 28, 486 (1982).

15. E. R. Henquín and J. M. Bisang, J. Appl. Electrochem., 35, 1183 (2005).

16. E. A. Kaminski and R. F. Savinell, J. Electrochem. Soc., 130, 1103 (1983)

17. G. Zhao, S. Duan, Q. Tian, and T. Wu, Metall. Trans. B, 21, 783 (1990).

18. D. Lindeman, Finite Elements in Analysis and Design, 22, 187 (1996).

19. A. Katagiri and Y. Miyazaki, J. Appl. Electrochem., 19, 281 (1989).

20. E. C. Dimpault-Darcy and R. E. White, J. Electrochem. Soc., 135, 656 (1988).

21. E. R. Henquín and J. M. Bisang, J. Appl. Electrochem., 38, 1259 (2008).

22. P. Peljo, E. Smirnov, and H. H. Girault, J. Electroanal. Chem., 779, 187 (2016).

23. J. Newman, Industrial \& Engineering Chemistry, 60, 12 (1968).

24. D. J. Pickett, Electrochemical Reactor Design, Elsevier, Amsterdam, (1979).

25. K. Zeng and D. Zhang, Prog. Energy Combust. Sci., 36, 307 (2010).

26. L. Sigrist, O. Dossenbach, and N. Ibl, J. Appl. Electrochem., 10, 223 (1980).

27. F. Hine, M. Yasuda, R. Nakamura, and T. Noda, J. Electrochem. Soc., 122, 1185 (1975).

28. C. W. Tobias, J. Electrochem. Soc., 106, 833 (1959).

29. R. E. D. L. Rue and C. W. Tobias, J. Electrochem. Soc., 106, 827 (1959).

30. F. Hine and K. Murakami, J. Electrochem. Soc., 127, 292 (1980).

31. H. Vogt, Electrochim. Acta, 78, 183 (2012).

32. H. Vogt, Electrochim. Acta, 26, 1311 (1981).

33. R. J. Balzer and H. Vogt, J. Electrochem. Soc., 150, E11 (2003).

34. H. Vogt and R. J. Balzer, Electrochim. Acta, 50, 2073 (2005).

35. B. E. Bongenaar-Schlenter, L. J. J. Janssen, S. J. D. Van Stralen, and E. Barendrecht, J. Appl. Electrochem., 15, 537 (1985).

36. K. Aldas, N. Pehlivanoglu, and M. D. Mat, Int. J. Hydrogen Energy, 33, 3668 (2008).

37. J. H. Ferziger and M. Perić, Computational Methods for Fluid Dynamics, Springer London, (2002)

38. H. H. K. Versteeg and W. Malalasekera, An Introduction to Computational Fluid Dynamics: The Finite Volume Method, Pearson Education Limited, Harlow, (2007).

39. D. Pletcher and X. Li, Int. J. Hydrogen Energy, 36, 15089 (2011).

40. B. V. Tilak, P. W. T. Lu, J. E. Colman, and S. Srinivasan, in Comprehensive Treatise of Electrochemistry: Electrochemical Processing, J. O. M. Bockris, B. E. Conway, E. Yeager, and R. E. White, Editors, p. 1, Springer US, Boston, MA (1981).

41. C. Kusik and H. Meissner, AlChE Symp. Ser., 74, 14 (1978).

42. S. Tanaka, N. Hirose, and T. Tanaki, Int. J. Hydrogen Energy, 25, 481 (2000).

43. H. Wendt, H. Hofmann, and V. Plzak, Mater. Chem. Phys., 22, 27 (1989).

44. E. R. Henquín, PhD Thesis, Universidad Nacional del Litoral, (2008), http://bibliotecavirtual.unl.edu.ar:8080/tesis/handle/11185/84

45. Y. Nishiki, K. Aoki, K. Tokuda, and H. matsuda, J. Appl. Electrochem., 16, 615 (1986).

46. C. Comninellis, E. Plattner, and P. Bolomey, J. Appl. Electrochem., 21, 415 (1991).

47. R. J. Gilliam, J. W. Graydon, D. W. Kirk, and S. J. Thorpe, Int. J. Hydrogen Energy, 32, 359 (2007). 